\title{
Idiopatic lobular necrotizing paniculitis
}

\author{
Letkova $\mathrm{K}^{1}$, Uhrinova $\mathrm{A}^{1}$, Bartosova $\mathrm{Z}^{1}$, Minarikova $\mathrm{Z}^{1}$, Vacula $\mathrm{I}^{1}$, Babal $\mathrm{P}^{2}$ \\ 2nd Department of Internal Medicine, Comenius University Hospital in Bratislava, Slovakia. \\ k.letkova@gmail.com
}

\begin{abstract}
: 42-year old patient was presented to our clinic with a fever lasting for seven months and a ten month history of subcutaneous nodules on all extremities and trunk. Further examination revealed anaemia, lymphocytopenia and elevation of inflammatory parameters and liver enzymes. Authors comment their difficulties in differential diagnostic process. The bone marrow biopsy and reappraisal of subcutaneous lesions confirmed idiopathic lobular panniculitis, known as Weber-Christian disease. A combined immunosuppressive therapy was followed by improvement of clinical state as well as laboratory parameters (Tab. 2, Fig. 3, Ref. 11). Text in PDF www.elis.sk. Key words: panniculitis, lymfadenopathy, hepatopathy.
\end{abstract}

Idiopathic lobular panniculitis (ILP) known also as WeberChristian disease is characterized by subcutaneous nodules, fever and various symptoms of systemic disease. Histopathological examination proves inflammation of adipose tissue (1).

Cutaneous condition similar to Weber-Christian disease was first described by German doctor Pfeifer in 1882. Weber covered a similar case in 1925 and referred the disease to relapsing nodular non-suppurative panniculitis. Christian contributed with another case in 1928 and added "febrile" to the name of the syndrome (1).

Weber-Christian disease occurs rarely. There are more case reports described in the literature than a real studies. No reliable epidemiologic data are available and prevalence or incidence remains unknown. It affects predominantly females between 4 th and 7 th decade (up to $75 \%$ of all cases), but is occasionally seen also in children or even newborns (2). Etiology has not been explained yet. It is considered an autoimmune inflammation of fat cells mediated by T-lymphocytes or circulating immune complexes $(3,4)$.

ILP is diagnosed "per exclusionem" in the differential diagnostic process. Biopsy and subsequent histological examination of subcutaneous lesions are crucial for the diagnosis (5).

No uniformly effective or standardized therapy for ILP has been established. Treatment modalities are usually based on immunosuppressive or antiinflammatory drugs (glucocorticoids, azathioprin, antimalaric drugs, cyclophosphamid, nonsteroidal antiinflammatory drugs, cyclosporine, tetracycline). In more severe cases, combination of drugs together with supportive treatment is needed $(5,3)$. Prognosis depends usually on the severity of the most common complication such as hepatic failure, which can be fatal (6).

2nd Department of Internal Medicine, Comenius University Hospital in Bratislava, Slovakia, and ${ }^{2}$ Institute of Pathological Anatomy, Faculty of Medicine, Comenius University in Bratislava, Slovakia

Address for correspondence: K. Letkova, MD, 2nd Department of Internal Medicine, Comenius University Hospital in Bratislava Mickiewiczova 13, SK-813 69 Bratislava, Slovakia.

Phone: +421.2.57290329, Fax: +421.2 .57290785$

\section{Case}

42-year old female, born on Madagascar, was admitted to our clinic because of a fever of unknown origin lasting seven months. During physical examination, many subcutaneous nodules over extremities and trunk except for the area of neck and head were observed (Fig. 1).

\section{Past history}

The patient initially reported occurrence of not painful itchy nodules in both breasts with spontaneous regression after 2 weeks. However, the accompanying overall malaise persisted. After 8 months, recurrent painful and itchy nodules in breasts with lymphadenopathy appeared. Magnetic resonance and biopsy with subsequent histomorphological examination lead to diagnosis of erythema nodosum with signs of vasculitis. New nodules appeared while others disappeared, leaving hyperpigmentation and atrophy of the affected skin. A high fever up to $40{ }^{\circ} \mathrm{C}$ was recorded. The

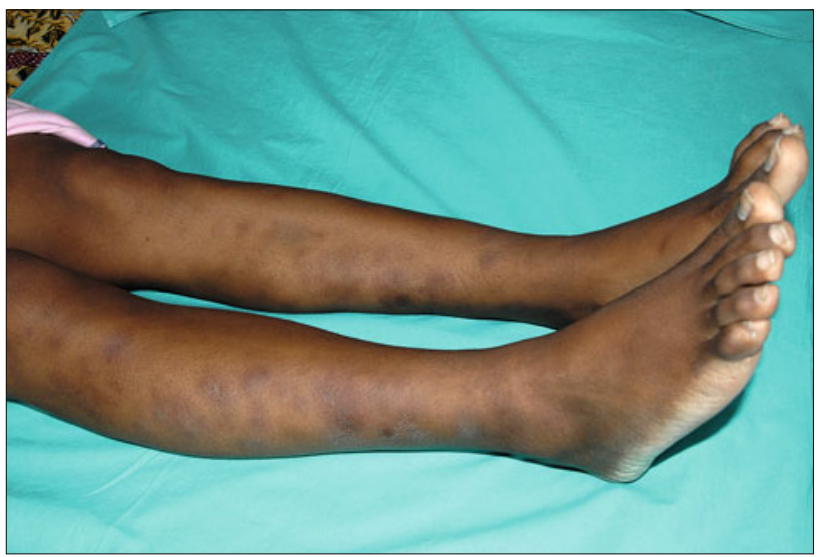

Fig. 1. Multifocal induration of the skin with hyperpigmentationSeptember 2010 (Photo: I. Vacula). 
patient was referred to a rheumatologic department and a therapy with prednisolone (10mg per day) together with hydrochloroquinine (200 mg per day) and aceclofenac was initiated. The patient was subfebrile and skin lesions regressed.

A couple of months later, the immunologist stopped the immunosuppressive therapy. Consequently the patient started to deteriorate and was admitted to the clinic of infectious diseases where the eventual infectious cause of the complaints was excluded. Administration of corticoids again helped her, she felt much better, but subcutaneous nodules persisted. The patient was released from the hospital without any specific treatment.

\section{Present complaints}

Physical examination on admission to our clinic: the patient was $165 \mathrm{~cm}$ high, had $50 \mathrm{~kg}$ of body weight, BMI was 18 , blood pressure was $90 / 60 \mathrm{mmHg}$, pulse 118 /minute, regular, body temperature: $38.5{ }^{\circ} \mathrm{C}$. Many subcutaneous nodules, approximately 4 $\mathrm{cm}$ large, located over trunk and extremities were seen (Fig. 1). Nodules were not painful, with hyperpigmentation on their surface, firmly adhering to the bottom. Axillary and inguinal lymphadenopathy and hepatomegaly was noticed. Clinically relevant laboratory tests are listed in Table 1.

Empiric antibiotic therapy with chinolons (pefloxacin) and ketoconazole was started, however, we failed to prove any infectious cause of fever and elevation of inflammatory markers. CT scan of the chest, abdomen and pelvis showed a couple subpleural
Tab. 1. Laboratory tests on admission.

\begin{tabular}{|c|c|c|c|}
\hline Parameter & Units & Value & Reference range \\
\hline Creatinine & umol/1 & 58 & $44-80$ \\
\hline Sodium & $\mathrm{mmol} / \mathrm{l}$ & 126,47 & $135-145$ \\
\hline Potassium & $\mathrm{mmol} / \mathrm{l}$ & 4,52 & $3,5-5,5$ \\
\hline Total Proteins & $\mathrm{g} / 1$ & 84,1 & $64-83$ \\
\hline Albumin & $\mathrm{g} / 1$ & 33,5 & $35-50$ \\
\hline Total Bilirubin & umol/1 & 7,5 & $0-20$ \\
\hline Aspartate transaminase & ukat/1 & 3,38 & $0,10-0,60$ \\
\hline Alanine transaminase & ukat/l & 1,45 & $0,10-0,60$ \\
\hline Gamma-glutamyltransferase & ukat/l & 1,22 & $0,08-0,65$ \\
\hline Alkaline phosphatase & ukat/l & 1,59 & $0,54-1,7$ \\
\hline C-reactive Protein & $\mathrm{mg} / \mathrm{l}$ & 69,04 & $0-5$ \\
\hline \multicolumn{4}{|c|}{ Blood count on admission. } \\
\hline Parameter & Units & Value & Reference range \\
\hline \multicolumn{4}{|l|}{ cell type } \\
\hline leukocytes & {$\left[10^{9} / 1\right]$} & 3,56 & $3,5-10,0$ \\
\hline neutrophils & & 3,23 & $2,4-6,3$ \\
\hline lymfocytes & & 0,27 & $1,1-3,7$ \\
\hline monocytes & & 0,04 & $0,08-0,75$ \\
\hline basophiles & & 0,60 & $0-1,5$ \\
\hline erytrocytes & & 4,09 & $4,0-5,2$ \\
\hline trombocytes & & 186 & $150-300$ \\
\hline hemoglobin & $\mathrm{g} / 1$ & 100 & $120-160$ \\
\hline HCT & - & 0,3 & $0,35-0,48$ \\
\hline $\mathrm{MCV}$ & $\mathrm{fl}$ & 73,12 & $82-96$ \\
\hline $\mathrm{MCH}$ & $\mathrm{pg}$ & 24,42 & $28,0-34,0$ \\
\hline
\end{tabular}

nodules in parenchyma of lung, enlargement of liver with steatosis, enlarged fatty degenerated lymph nodes in both axiles, multiple

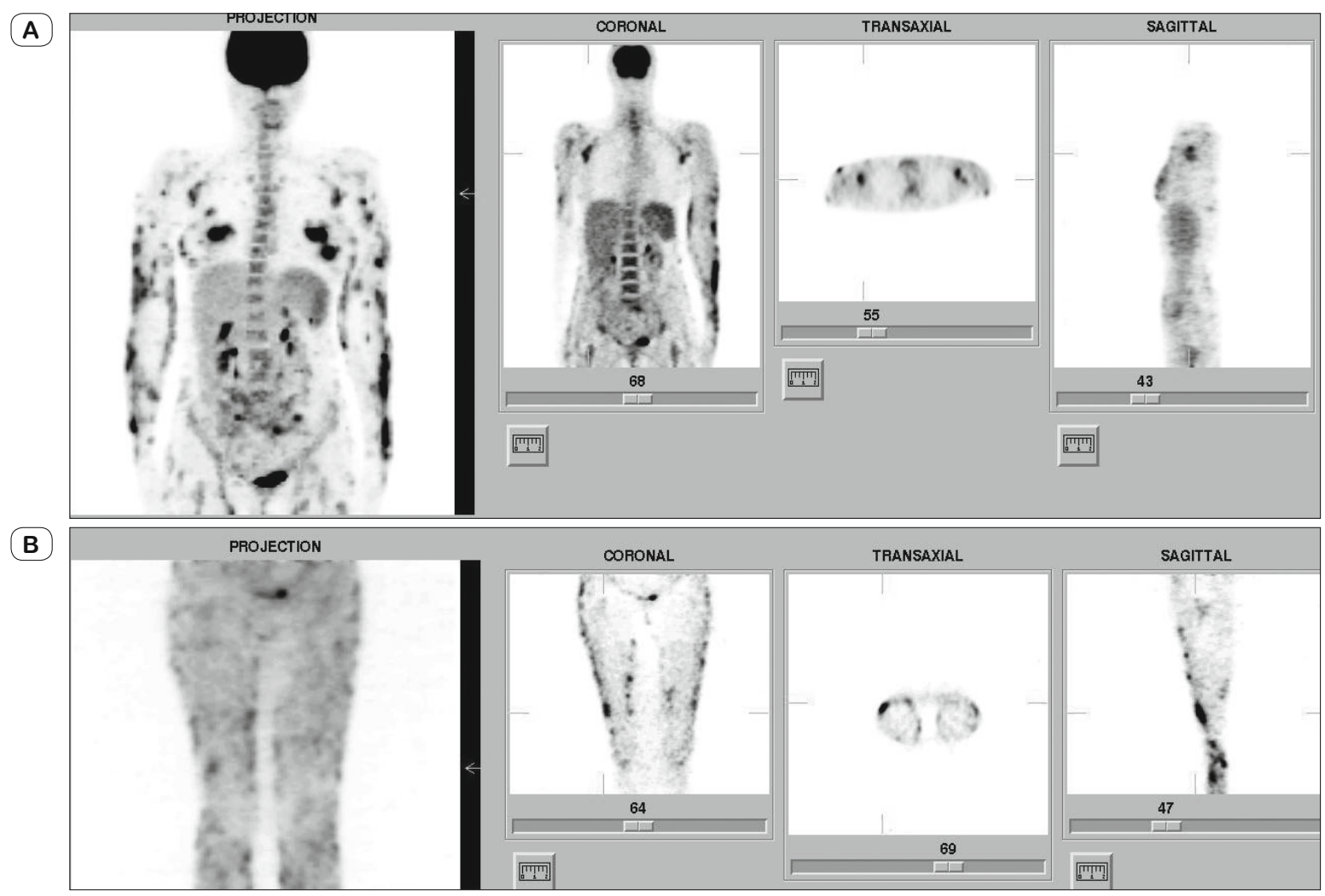

Fig. 2 (A, B). PET (Positron emission tomography) scan - the whole body in the coronal, sagittal and frontal position. Increased ${ }^{18}$ FDG metabolism in the skin, slightly increased ${ }^{18}$ FDG metabolism in the liver. $\left({ }^{18} \mathrm{FDG}-{ }^{18}\right.$ Fluorodeoxyglucose). 

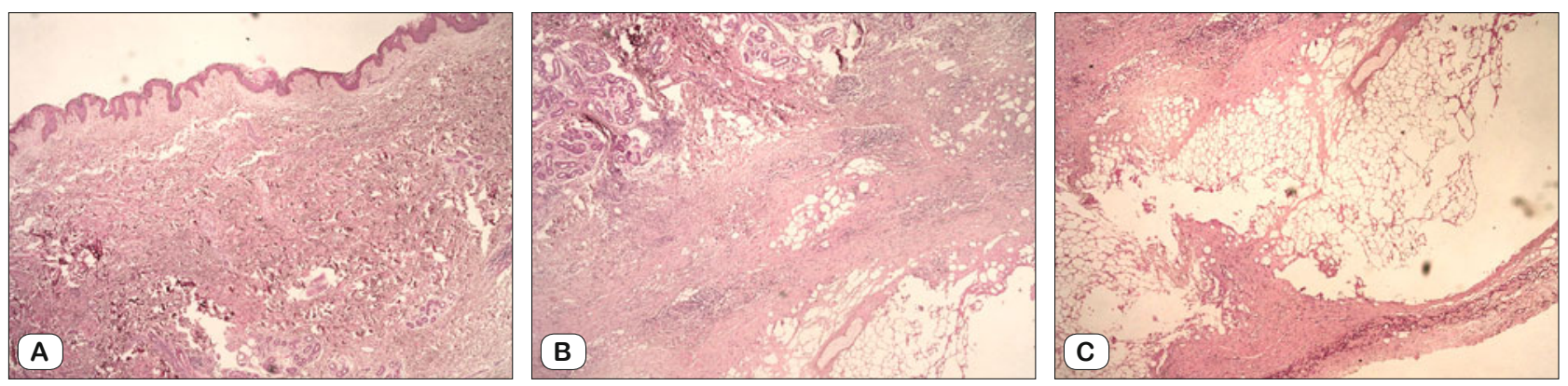

Fig. 3. Subcutaneous infiltrate. Epidermis not effected (A). In the subcutaneous adipose tissue: perivascular lymphocyte and plazmocyte infiltrations, without clear signs of vasculitis, without fibrin exudation, without thrombosis (B). Focal necrosis of adipose tissue in the lobules with minimal involvement of granulocytes; with marked histiocytic and granulomatous reaction; addition of not numerous multi-core cells (C).

subcutaneous infiltrates in abdomen, chest and gluteal area and infiltration of mesenterial fat tissue as well. A positron emission tomography with fluorodeoxyglucose (FDG-PET) (Fig. 2) demonstrated areas of increased metabolic activity in subcutaneous tissue, lymph nodes in both axiles and groins and basal ganglia bilaterally. We also performed trepanobiopsy of bone marrow that revealed reactive polyclonal plasmocytosis with lymphocyte activity during histological examination.

Antibiotic therapy was stopped. During the hospitalization elevation of liver enzymes was detected. We continued symptomatic treatment with antipyretic drugs (ibuprofen) and hepatoprotective agents. Extirpation and histological examination of lymph node from left inguinal area did not help with the final diagnosis. Only the reevaluation of subcutaneous lesion from the time of the first appearance of patient's symptoms proved the diagnosis of ILP. Therapy with corticosteroids in pulse regimen (metylprednisolon $250 \mathrm{mg}$ during first 5 days) with subsequent treatment with prednisone $60 \mathrm{mg}$ and cyclophosphamid $1 \mathrm{mg} / \mathrm{kg} /$ day was started. Patient responded to this treatment. A gradual elimination of subcutaneous

\section{Tab. 2. Classification of panniculitis (5).}

\begin{tabular}{l}
\hline 1. Septal panniculitis \\
\hline Erythema nodosum \\
Subacute nodular migratory panniculitis (Vilanova disease) \\
\hline 2. Lobular panniculitis \\
\hline Christian-Weber disease (febrile relapsing non-suppurative panniculitis) \\
Rothman-Makai syndrome (lipogranulomatosis subcutanea) \\
Subcutaneous adipose diseases of the neonate \\
Post-steroid panniculitis \\
Calcific panniculitis \\
Enzymatic panniculitis - pancreatic, alpha-1-antitrypsin deficiency \\
Physical or pressure panniculitis \\
Cytophagic panniculitis \\
Lipodystrophy syndromes \\
Panniculitis in systemic connective tissue diseases (scleroderma, myositis) \\
\hline 3. Mixed panniculitis \\
\hline Lupus profundus (panniculitis) \\
Erythema nodosum-like lesions in Behcet's syndrome \\
\hline 4. Panniculitis with vasculitis \\
\hline Vasculitis of small blood vessels \\
Medium-sized vessel vasculitis (small arteries or arterioles) \\
Polyarteritis nodosa \\
Erythema induratum (nodular vasculitis) \\
\hline
\end{tabular}

nodules and disappearance of fever was followed by normalization of inflammatory markers. Patient was discharged home.

\section{Discussion}

Panniculitis refers to a heterogeneous group of disorders characterized by inflammation of subcutaneous adipose tissue (7) (Tab.2). In our case, the skin lesions were characteristic for ILP (Fig. 3) and our description is in agreement with the literature (5). Using the available laboratory and imaging examination modalities the possibility of infection, deficiency of alpha-1-antitrypsin, diabetes mellitus, sarcoidosis, inflammatory bowel diseases, solid tumors, vasculitides and other autoimmune diseases mentioned in the literature $(8,9)$ were ruled out to conclude the diagnosis. The most difficult problem was to exclude lymphoma imitating panniculitis. Other authors also confirm our experiences and stress the key role of histological examination of the biopsy specimens before initiation of any treatment $(10,11)$.

Visceral parenchymatous organs (liver, spleen, myocardium, adrenal glands) as well as visceral adipose tissue (mesenteric, omental, pericardial and pleural tissue) can be involved in ILP cases (5). There has been a wide spectrum of damaged organs described in the literature including bone marrow, lungs, small and large intestine and kidneys. Occasionally, also myalgia, congestive heart failure and inflammation of the eye can occur (5). In our case, the liver damage seemed to be a prognosis limiting problem.

As there are no available guidelines for the treatment, the choice of the immunosuppressive drug as well as the dosage or regimen of corticosteroid therapy depends on the local practice or experiences of the responsible physician. Our case description contributes to experiencie proving a high effectiveness of the pulse regimen of corticoid administration, followed by maintaining dose in combination with cyclophosphamide.

\section{Conclusion}

Presented case illustrates the usual problem of every patient suffering from a rare disease - time to diagnose and appropriate treatment is too long. ILP represents a disease with a broad spectrum of symptoms and thus also a difficult differential diagnosis 


\section{$377-380$}

that requires patience of the physician. The biopsy and histomorphologic evaluation should be decisive in the diagnostic process. The immunosuppressive treatment is usually effective but should not be disrupted suddenly and the patient should be followed by an experienced physician. We hope that our experiences will also can contribute to higher awareness of this rare disorder.

\section{References}

1. Pongratz G, Ehrenstein B, Hartung W. A patient with Pfeifer-WeberChristian Disease - Successful Therapy with Cyclosporin A: case report. BMC Musculoskel Dis 2010; 11 (1): 18.

2. Mamishi S, Mojtahedi SY, Mahjoub F. Weber-Christian disease in a 9 month old boy: report of a case. Acta Med Iran 2002; 40 (1): 16-19.

3. Wasserman JM, Thung SN, Berman R. Hepatic Weber-Christian Disease. Semin Liver Dis 2001; 21 (1): 115-118.

4. Ter Poorten MA, Thiers BH. Systemic Weber-Christian disease. J Cutan Med Surg 2000; 4 (2): 110-112.
5. Hugh A A, Bainborough AR. Weber-Christian Disease with visceral involvement. Canad Mes Ass J 1963; 89 (22): 1138-1142.

6. Hinata M, Someya T, Yoshikazi H. Succesful treatment of tseroid-resistant Weber-Christian disease with biliary ductopenia using cyclosporin A. Rheumatology 2005; 44 (6): 821-823.

7. Lukáč J. Panikulitídy. 321-325. In: Lukáč J et al (Eds). Systémové choroby spojivového tkaniva (systémové autoimunitné choroby). Pieštany; Tlačiareň PN print s.r.o, 2010.

8. Gavorník P(Eds). Ateroskleróza. Bratislava: Vydavatel'stvo UK, 1999: 167-169.

9. Gavorník P (Eds). Všeobecná angiológia. Bratislava: Vydavatel'stvo UK, 2001: 181-182.

10. Ehrenfeld M, Abu-Shakra M, Buskila D. The dual association between Lymphoma and Autoimmunity. Blood Cells Mol Dis 2001; 27 (4): 750-756.

11. Sajben FP, Schmidt C. Subcutaneous T-cell lymphoma: a case report and additional observations. Cutis 1996; 58 (4): 297-302.

Received August 28, 2012. Accepted March 8, 2014. 